\title{
From genogram to genograph: using narrative means to contextualize social reality in the counselling session
}

\author{
PJM VAN NIEKERK, RL VAN NIEKERK, H Mushonga AND A DOGGER*
}

\begin{abstract}
This article addresses a process that occurs when applying narrative therapy during a counselling session, namely moving away from the genogram towards the more effective genograph. Narrative therapy implies that we often talk and share stories about ourselves and that these stories are usually within a social context, whether it is our families, personal relationships or work. Stories are an important aspect in narrative therapy and therefore the counsellor must be aware of a family's different contexts both as a family system, and as a group of individual members. The article takes as point of departure the thoughts of Charles Horton Cooley and George Herbert Mead and their influence on the development of the 'self' and the construction of our social reality within this process. It further argues in favour of the use of a genograph as a symbolic representation of the personal meanings of a family member's experience of the dominant and alternative stories with which they live.
\end{abstract}

Keywords: Narrative therapy, counselling, family counselling, genograph, genogram, symbolism, social reality, social self, self, family history.

\section{Introduction}

To understand counselling from the approach of the genogram (a tool which allows the counsellor and the family to examine the family in its intergenerational context) to the approach of the genograph (a visual display of the social context of the client), means to gain insight into one's own story. The process further depicts the diachronic axis, which concerns the history of the clients and/or those close to them, and the synchronic axis, which concerns the present circumstances confronting them, in order to manage or change relations which clients maintain, at a particular moment, with those around them. To do that, one must take note of and try to understand the self and the

* PJM van Niekerk, School of Behavioural Sciences, North-West University; RL van Niekerk, Department of Psychology, University of Johannesburg; H Mushonga, Anthropology and Development Studies, University of Johannesburg; A Dogger, School of Behavioural Sciences, North-West University. 
complex systems that are part of your life as well as the process of counselling. This is where the contribution of Charles Horton Cooley and George Herbert Mead in their work on symbolic interactionism becomes relevant. Hubert Blumer (1969:1) states that the term symbolic interactionism has come into use as 'a label for a relatively distinctive approach to the study of human group life and human conduct'. Symbolic interactionism can thus be seen as one explanation of the way in which the 'self' and the 'other' shape and influence one another in various life contexts.

Within the African context, religion and culture are probably the most influential determinants of meaning in people's lives. People, to a considerable extent, interpret experiences of the most intimate and the most public events according to their religion and/or culture. By their very nature, religion and culture give meaning to events and experiences worldwide. Religions and cultures carry within them history, beliefs, ways of doing things, and processes of communication. Religion informs a narrative in which there is a continuous movement towards a valued goal (Gergen 2001:105). In this regard a renewed and deepened appreciation for the diversity of human spirituality leads to a re-evaluation by many mainstream mental health professionals of the role of religion and spirituality in counselling (Richards \& Bergin, 1999). Genia (2000) refers to research suggesting that a strong religious commitment is associated with positive mental health. Consequently, the need for a spiritual strategy emerges (Richards \& Bergin, 1999) in a context where many forms of psychotherapy do not address religious issues (Genia, 2000).

Richards and Bergin (1999) refer to literature reports suggesting that many clients can be successfully treated only if their religious issues are addressed sensitively and proficiently. Their treatment would not have been completely successful if their counsellors had not addressed their beliefs appropriately. Many therapists now consider spiritual beliefs and behavior as possible resources for promoting therapeutic change. Genia (2000) indicates that these are clients for whom conventional religious beliefs and practices are important. However, few counsellors are adequately trained or prepared to deal effectively with such issues (Richards \& Bergin, 1999). The challenge would be to conceive of religion sufficiently and in broad enough terms to encompass the diverse expression of today's religious pluralism (Wulff, 1997) and the multiplicity of possible meanings generated in people's lives.

Several boundaries and borders exist around each individual. These include the various ways through which we attempt to give meaning to our lives. These boundaries and borders are usually linked to our thoughts or cognitions, feelings or emotions, deeds or behaviour, biological or physical and religious or spiritual spheres of life, as well as the survival mode, Dr. Walter B Cannon's fight or flight response (Backus, 1986:77). 
These elements, especially the interaction between the five interdependent contexts, are important for counselling and are discussed in detail as part of the process from genogram to genograph by using narrative means to contextualize social reality in counselling It is important to mention that 'narrative means' and 'storytelling' are the same thing. When we make use of narrative, we are actually using storytelling as a method of counselling. Therefore this article will refer to both narrative and story where applicable. Before we start with the self or social self, we need to explain what a genogram is.

\section{What is a genogram?}

Murray Bowen's model and views on self-differentiation gave rise to the genogram; a tool that allows the counsellor and the family to examine the family in its intergenerational context. The genogram also provides a well-defined structure and method for gathering information about the family (Becvar and Becvar, 1996:155). A genogram is therefore a map that provides a graphic picture of the family structure over several generations and gives a schematic representation of the main stages in the family lifecycle together with the attendant emotional processes. In this regard, the genogram functions as a metaphor during counselling in which the family members can take a metaperspective (a bird's-eye view) on the family and how every member is positioned within the family as a whole. The standard repertoire of symbols was established by Bowen (Carter and McGoldrick, 1980) and includes:

- names and ages of all family members;

- exact dates of birth, marriage, separation, divorce, death and other significant events;

- notations, with dates, about occupation, places of residence, illness, and changes in life course, on the genogram itself; and

- information on three or more generations.

The genogram therefore represents the story of the family members involved.

When evaluating a family's place in the lifecycle, we have found genograms and family chronologies to be useful tools. They provide (at a glance) a three-generational picture of a family and its motion through the lifecycle. Genograms can elucidate the family lifecycle framework and provide an understanding of the lifecycle. The family lifecycle is a complex phenomenon. It is a spiral of family evolution as generations move through time in their development from birth to death (Carter and McGoldrick, 1989:164).

One can compare this family process to music or sport. In music, the meaning of individual notes depends on their rhythms in relation to 
one another and with the memories of past melodies, as well as the anticipation of those yet to come. In sport, the decisions one makes influence the flow of the game that might contribute to the successes or failures of the team as a whole. Genograms are graphic pictures of the family history and pattern, showing the basic structure, demographics, functioning, and relationships. They are shorthand used to depict the family patterns at a glance. Figure 1 shows a simplistic example of such a genogram.

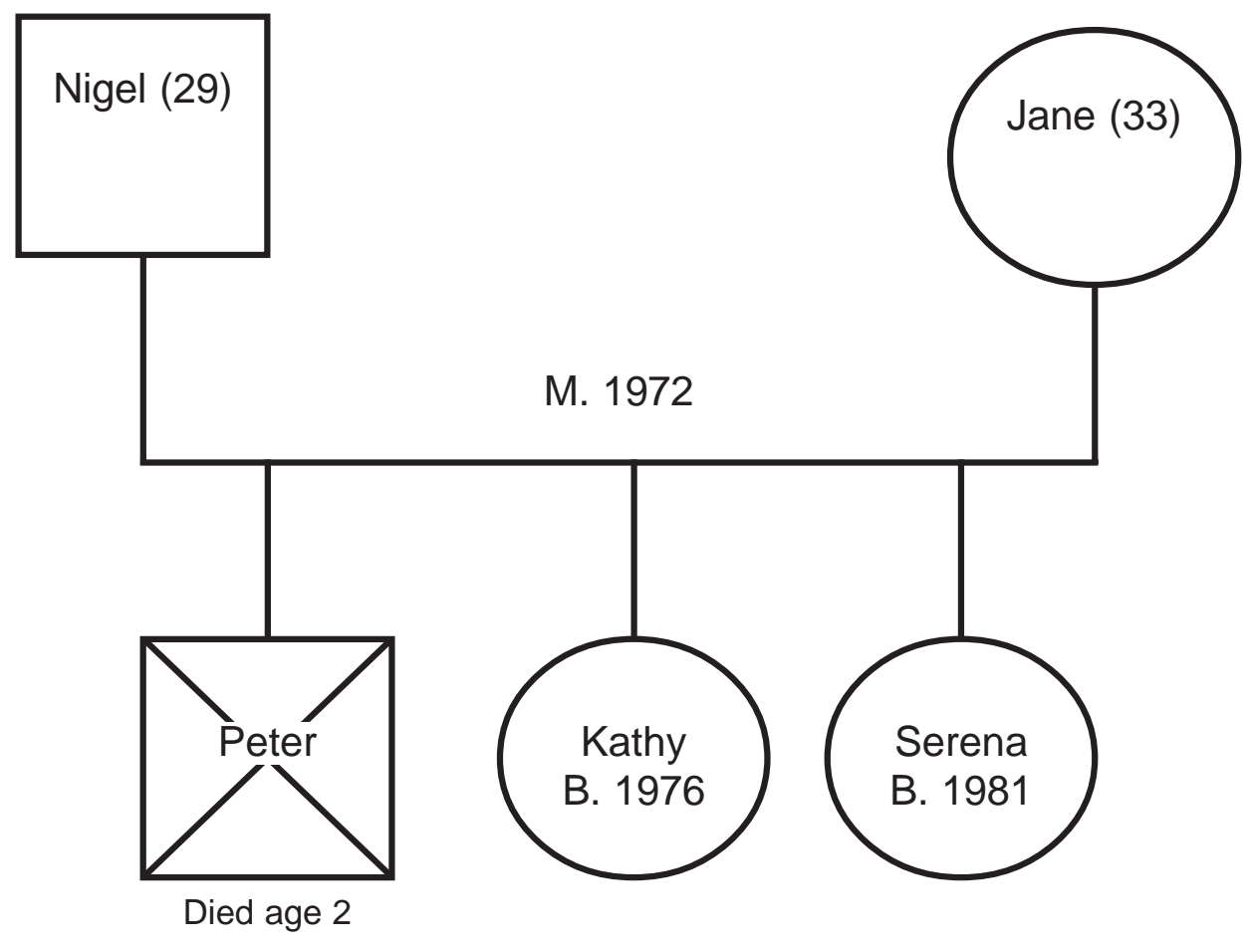

Figure 1. A visual representation of the family story of Nigel and Jane Ford.

\section{The self/social self}

Modernist approaches to the study of the self are based on the assumption that the self exists as something that can be discovered and described in the same way as any other object (Crossley, 2000). In reaction to such a stance, a social constructionist approach indicates that the experience of self exists in the continuous interchange with others whose narratives are woven into reciprocal relationships with others (Weingarten, 1991). 'Who I am' and the nature of one's actions are negotiated and defined within relationships (Gergen, 1999). The idea 
of self is formed through social interaction within particular cultural contexts, which means that there could be no essential self. The self is rather described as a process or activity that occurs in the spaces between people. Selves are socially constructed through language and maintained in narrative. Different selves come forth in different contexts and no one self is truer than the other. However, one self is preferred in a specific context rather than the other. These preferred selves grow and develop to constitute the experience of self (Freedman \& Combs, 1996). One real self may indeed generate multiple self-constructions, a concept that is crossing the bridge from singularity (referring to the modernist approach of a single self or personality) to poly-vocality (Gergen, 2001).

The extent of this article, with the genogram in mind, allows the authors to focus on the social context and its dynamics within the construction of the reality of the individual. Symbolic interactionism allows us the opportunity in sociology to focus on the construction of the self in terms of the relevant contexts.

Charles Horton Cooley (1902:207) was one of the first sociologists to study socialization and the sense of self. Cooley is curious about how human beings come to think of themselves as an 'I' or 'Me'. He is also concerned with what kind of person one thinks one is. Cooley eventually decided that people come to think of themselves as a 'self' through a combination of biological and social processes. He believes that even a newborn infant has a consciousness, as well as desires or needs which he called acquisitiveness.

From the beginning, children experience desires and needs. As they grow, they see other people expressing similar desires and needs by saying 'mine' or 'I want'. Children learn that 'mine' is associated with things a person either possesses or wants to possess. Cooley argues that objects that a person labels as 'mine', are those that society defines as 'theirs'. A person's self consists of thoughts, emotions, and actions a person sees as integral to their sense of identity (Wallace \& Wallace, 1989:80).

People see themselves as being the way they are, in part, because others reflect their selves to them. Wallace and Wallace elaborate on this statement by adding that

(P)eople look into the mirror to see what they look like physically and look to other people to see what they are like as persons (1989:80).

Cooley called this phenomenon the looking-glass self, or the image of self reflected by others and he states that:

As we see our face, figure, and dress in the glass, and are interested in them because they are ours ... so in imagination we perceive in another's mind some thought of our appearance, manners, aims, deeds ... and are variously affected by it (1902:17). 
Van Niekerk, Van Niekerk, Mushonga and Dogger

Mead adds that

(A)s a mirror reflects your physical appearance, so symbolic interaction provides a mirror in which the self is constructed and reflected (Jordaan \& Jordaan, 1998:621).

The looking-glass self develops when an individual imagines how he or she appears to others, imagines his or her response, and responds to that by creating a sense of self, modified by his or her reaction. According to Cooley

(A) self of this sort seems to have three principal elements: the imagination of our appearance to the other person; the imagination of his judgment of that appearance, and some sort of self-feeling, such as pride or mortification ... we always imagine, and in imagining share, the judgments of the other mind. A man will boast to one person of an action ... which he would be ashamed of to another (1902:17-18).

Mead (Wallace \& Wallace, 1989:81) also agrees with Cooley's idea that there must be a link between the individual and his/her social context. In this regard, Mead (1934) describes the self within the context of dialogue, and conceptualized the self within a process where dialogue between the self and others leads to a reflexive self. According to Hermans (1999), Mead indicates that the self does not just constitute a slavish experience and reflection of social influence, but is an innovative agent in a process of inspiration to take action. Mead is especially concerned with how social and human qualities of mind and self originate and he defines the self as a reflective process - i.e. 'it is an object to itself' (Mead, 1934:136). He believes that the self has two parts which he calls the 'I' and the 'Me'. The 'I' is the conscious, spontaneous, and creative part of the self: the part that experiences pleasure, pain and spontaneous impulses. Whereas the 'I' is inborn, the 'me' is other people's definition of who one is. It includes the internal controls taught by society. The 'I' accounts for what people want to do, and the 'me' accounts for what people feel they should do. The 'me' makes people aware of how they appear to others and how they fit into a social setting.

Mead (1934:197) also defines the 'me' as a 'conventional habitual individual' and the 'I' as the 'novel reply' of the individual to the generalized other.' Both Cooley and Mead believe that the self arises only through social interaction and also that every individual must develop a self. Because the 'I' is inborn, the developmental process is one of establishing the 'me'. According to Mead (Wallace \& Wallace, 1989:81) this development proceeds through three basic stages. In Stage 1 an infant is exclusively 'I'. They are impulsive and know nothing of the social environment or the internalized controls of the 'me', which will allow them to enter social life as an active participant.

In Stage 2 the 'me' begins to develop through play. When this playing merely involves throwing the ball or hitting it with a bat, the child is, 
in Mead's terms, taking on the role of the other, the 'other' being the sibling. According to Mead, childhood socialization largely depends on significant others; persons with whom an individual has intimate and long-term contact. In other words, new members of society become what society wants them to become because they strive to please significant others who are already members of that society and who already follow its norms (Wallace \& Wallace, 1989:81).

In Stage 3 the 'me' fully develops as the child learns to respond to the generalized 'other'. This means that the child takes into account the broader social community - the community beyond the significant others. As children develop the 'me' through play and other social interactions, they learn to function in complex social structures. Mead and others believe individual self-consciousness is necessary for organized human society to exist. Wallace and Wallace state that:

In one sense, society is like a machine, and when individuals interact, they do so as parts of the machine (1989:81).

With this in mind the symbolic interactionists ask: how do people define reality and social reality? According to symbolic interactionists, symbols play a central role in social interaction. A symbol is any kind of physical phenomenon, for instance a word, object, colour, sound, feeling, odor, movement or taste to which people assign a meaning or value. However, the meaning or value is not evident from the physical phenomenon alone and people must share a system of symbols if they are to communicate with one another. Without some degree of mutual understanding, encounters with others would be ambiguous and confusing (Ferrante, 1998:50-53).

\section{Symbols}

Taking the abovementioned into account, Mead (1934) focuses on how we use symbols, including language, and how our use of symbols influences our social development and social life. Everyday events, in which at least two people communicate and respond through language and symbolic gestures, to affect one another's behaviour and thinking, are proof that social context is present. Sociologists also assume that any social interaction reflects forces beyond the obvious and the immediate. Hence, they strive to locate the interaction according to time or history, and place or culture. When sociologists study social interaction, they seek to understand and explain the forces of context and content (Ferrante, 1998:160-161).

Social constructionist theorists see ideas, concepts and memories as being co-constructed or co-created (Anderson \& Goolishian, 1988) with social interchange (Kotze \& Kotze, 1997) and mediated through language (Hoffman, 1992). Language is seen as more than just a way of

TD, 2(2), December 2006, pp. 473-490. 
connecting people; people exist in language, where meaning and understanding are derived from the logic of symbols, signs and the grammatical structure of language (Kotze \& Kotze, 1997). Meaning and understanding come about in language (Anderson \& Goolishian, 1988). From a social constructionist point of view the focus is not on the individual person but on 'the social interaction, in which language is generated, sustained and abandoned' (Gergen \& Gergen, 1991). Language constitutes people's lives, which they understand through socially constructed narrative realities that give meaning and organization to their experience (Anderson \& Goolishian, 1992).

Kotze \& Kotze (1997) indicate that language, discourse and narrative are intertwined concepts. Narratives refer to the stories of people's lives and White \& Epston (1990) describe them as the experiences of events in sequences across time. It is experienced in such a way as to arrive at a coherent account of themselves and the world around them. Dominant narratives in society (stories society tells and lives over and over) could become part of a person's life, shaping and constituting it, while others (alternative stories) become a part of a person's life, but never become part of a shaping narrative.

In understanding context and content, language is essential to the individual in order to construct his own social reality. Written and spoken words represent objects or ideas and are essential when we construct our reality or social reality. Therefore we need to discuss social contexts with regard to the social self, social reality, and the family being part of a social structure.

\section{Social contexts}

Defining the self and the family within a social context (a social constructionist view to reality) does not provide a theory in the sense of a body of laws or causal process theory, but must be regarded as an approach (Launer, 1996), a lens (Hoffman, 1992), or a stance (Anderson, 1992). In this regard all ideas, concepts and memories arise from social interchange and are mediated through language (Hoffman 1992:8). Thus, knowledge is socially constructed (rather than discovered) and its validity in counselling is measured by congruence with shared understanding (Bohan, 1990). Kuhn (in Bruffee, 1986) agrees with this description, saying that entities normally referred to as 'real', knowledge, thought, facts, texts, selves, and so on are communitygenerated and community-maintained linguistic or symbolic entities. Such knowledge is inevitably influenced by the social context from which it derives.

Clyde Kluckhohn (1985:124) writes that every language is also a special way of looking at the world and interpreting experiences. People 
explain what they understand through language and stories. This reflects their reality in terms of the contexts involved. When sociologists say that reality is constructed, they refer to the fact that people assign meaning to interaction or to certain events. When people assign meaning, they almost always emphasize certain aspects of an event and ignore others. By doing so they create a unique story of their own that is distinct from any other. This unique story incorporates the self, the social self and the social contexts involved in the individual's life. With this in mind the reality involves the self, the social self and the way the unique individual sees his or her own story which seems real. This corresponds with William and Dorothy Thomas:

If people define situations as real, they are real in their consequence (Thomas \& Thomas, 1928:572).

Humankind thus interprets their social situation in their own way, influenced both by what they have internalized in the course of their primary and secondary socialization and by their own creative imaginative effort. In short, an individual's typification, constructions and interpretations of reality becomes a guide to everyday action, and when these are reciprocally shared by many others, institutionalization may be said to have taken place.

As stated by Cortazzi (1994:157-170), stories of personal experiences crop up repeatedly in, for example, informal conversations, doctorpatient talk, in the proceedings of courts, in psychotherapy sessions, newspapers articles and in social science research interviews. Stories are, of course, an important genre in their own right. It is probably the first to be acquired at home and the most exploited in the early stages of learning in schools. It has certainly been the most studied and it is increasingly recognized as a major role player in the reproduction of culture and society. To broaden our view of social context, we need to discuss stories, together with narrative, in order to understand why they are part of our social contexts.

According to several authors mentioned in Cortazzi (1994:161), we use stories to (a) translate knowing into telling, (b) distance ourselves reflectively from the events (Moore and Carling, 1988), (c) (re)interpret our experiences, (re)evaluate them and (re)position ourselves vis-à-vis story content and social values (McKay, 1993), and (d) endow our lives with meaning across time (Gergen \& Gergen, 1993). However, all these narrative functions are socially situated and narrative itself is constitutive of them, according to current social constructivist perspectives. Mumby states that

Narrative is a socially symbolic act in the double sense that (a) it takes on meaning only in a social context and (b) it plays a role in the construction of that social context as a site of meaning within which social actors are implicated (Cortazzi 1994:161).

TD, 2(2), December 2006, pp. 473-490. 
Goffman (Cortazzi, 1994:162) sees personal narratives as 'strips of personal experiences' from the teller's past, which is 'replayed', not as a mere reporting, but rather as a re-experiencing, directly for the teller, vicariously for the audience. Tannen's research also supports the point that narrative is influenced by context and culture. There is also the possibility, supported by Middelton and Edwards as well as by Tonkin that narrative form and the context of recall, shape story memories as much as memories shape stories (Cortazzi, 1994:162).

The self is continuously constructed actively. What is constructed is, according to Connell (1987), the coherence, understanding and reality of a person's social relations over time. While people are living their lives, they are continuously shaping themselves as characters or personalities, in the way in which they reconcile and work the raw material of their social contexts. The narrative approach to the self understands that people's ability to express themselves in narratives starts with the telling of their experiences. In striving to make sense of life, White and Epston (1990) indicate that a person has the task of organizing these experiences and events in sequence over time, in such a way that it ends in a coherent representation of themselves and the world around them. Such a representation is described as a story or self narrative (Gergen en Gergen, 1984). Burger (2004) indicates that Ricoeur constructed the term 'narrative identity' to express our experience of identity as a continuous story, in which our actions and experiences are connected as a series of events.

A few remarks should be made regarding the social context of the narrative identity. In this theory of personal narratives, there is a strong emphasis on the individual interpretation and attribution of meaning to situations and events. However, it is not an individualistic approach, because we do not write the personal narrative in a relational vacuum. For every individual there is a range of relationships within the social context. The personal narrative of one touches the narratives or stories of others. The way this social context influences the personal narrative may be understood in terms of a narrative public, which we address in telling our stories. This public can also include a total society with all its contexts. The personal narrative is the central story in which events and situations are being told and interpreted. Relational theories such as symbolic interactionism stress the fact that the interpretational process is a highly social phenomenon.

Such frameworks are helpful when examining the kinds of complex teller-audience roles and narrative purposes, such as those found in therapeutic narrative dialogues. In these instances, a therapist and client (re)construct the client's life story together, often out of chronological sequence. According to Schachter and Hoffman as well as Peseschkian (Cortazzi, 1994), traditional religious stories or personal narratives may be told by the therapist so that clients identify with 
story characters, or the situations, and reflect on and solve their own problems. Clients usually tell their stories, in part, to themselves as well as to the counsellor. The narrated self is 'a mutual interpretation of past and present' (Cortazzi, 1994:162). The latter coincides with Gregory Bateson's (1979) views regarding mind and nature. According to Bateson there is

a larger mind of which the individual's mind is only a subsystem [ ... ] in total interconnected social system and planetary ecology (1979:14).

Further, we must think in terms of stories that are shared by all minds. Such stories establish the connections between parts, "the very root of what it is to be alive' (Bateson, 1979:14). The concept of mind and nature is simple, yet profound in its implications for our experience of self, of other humans, and of a storied reality. The forms of our relationships with self, others, and creatures and things necessarily take the form of the way we story others and ourselves.

It is important for us to mention first-order cybernetics and secondorder cybernetics since aspects of cybernetics are relevant to our discussion of stories. First-order cybernetics has to do with the observer observing an object. This order relies on information, control and feedback. First-order cybernetics is therefore consistent with the previous statement that the form of our relationships with self, others, creatures and things necessarily take form in the way we story others and ourselves. We rely on information and feedback when we story our experiences.

Second-order cybernetics is when the observer becomes part of what is being observed. In other words, what is being observed has an influence on the observer and therefore we become participants in the construction of stories. Second-order cybernetics is therefore consistent with Bateson's perspective that stories establish the connections between parts, the very root of what it is to be alive. Second-order cybernetics is the stories we tell ourselves and that which we perform in the theatre of life, which is often our experienced reality. According to Mair:

(S)tories are habitations. We live in and through stories. They conjure worlds. We do not know the world other than as a story world. Stories inform life. They hold us together but can keep us apart. We inhabit the great stories of our culture. We live through stories. We live by the stories of our race and place. It is important to grasp this enveloping and constituting function of stories. We are locations where the stories of our place and time become partially tell-able (1988:127).

Howard makes the following statement:

(O)ur stories are the houses, the families, the communities, cultures, nations, and cosmos in which we live (Becvar \& Becvar, 1996:348-349).

Thus, to deny the existence of the social reality in one's story is nothing 
less than to underestimate the power of that story and the reality constructed in time and space. In counselling, the counsellor should take note of not only the self, but also the social context of the client. This enables the counsellor to understand his/her client, and the clients on the other hand learn to understand themselves.

Considering all the points of view stated in this article, it becomes evident that all aspects must be taken into account when discussing the shift from genogram to genograph. The author therefore wishes to stress that he acknowledges and underwrites these statements and thoughts, but also finds it crucial to emphasize that the genogram, or the family story, has to develop into a visual representation, or picture, which is referred to as the genograph which visually displays the social contexts of the client. This visual representation enables both client and counsellor to come to an understanding of the client's contextual reality that is, the reality clients perceive within their social contexts. The following discussion will focus on the question, 'What is a genograph?'

\section{What is a genograph?}

Since the family is structured within several contexts and each family has a dominant story. A new concept namely the genograph makes an attempt to place the family within its dominant context. The genograph can be seen as a photograph of the family structure; it becomes a visual representation of what the family context looks like. Such a visual representation can be seen as an expression of constructed meaning about the family. Atwood and Seifer (1997) indicate that the process of socialization leads to the internalization of socially constructed meanings. A person's reality is maintained by the development of a personal sense of self that is congruent with his/her social constructions and applied symbolically to the family.

People attempt to match or reject their own personal constructs against the dominant social constructions. A dialectical (paradoxical) relationship develops at times between the individual realities and the socially constructed meaning if the constructs are incongruent with one another. Hare-Mustin and Marecek (1988) indicate that these paradoxes arise because every representation conceals and reveals at the same time. These paradoxes in constructions, called difference by Derrida (Atwood, 1997), challenges people's conventional thought, revealing meanings that are present but obscured in the dominant social view. Atwood (1997) calls these obscured views the 'ever present but lurking shadow scripts of a family', while White \& Epston (1990) refer to it as 'subjugated knowledge'. This is where the most opportunity for change during counselling can be found. A genograph tends to capture these shadow scripts and present the counsellor with the 
projected meaning it has for the family member in his/her family story. Individuals are part of a family story but also part of a social story. To understand the contexts involved in the individual's life that make up part of the genograph, one must give a visual representation or a social picture to understand the involvement. Becvar and Becvar (1996:155) state that the following individual and family characteristics should be included in the genograph: cultural and ethical origins, socio-economic status, religious affiliation, physical location, and the frequency and type of contact between the systems.

The following visual representation, as portrayed in Figure 2 is an example of a genograph describing the social contexts of a family and its members.

Figure 2: Genograph of Nigel and Jane Ford: A visual representation of the dominant context (education) in the story of Nigel and Jane Ford

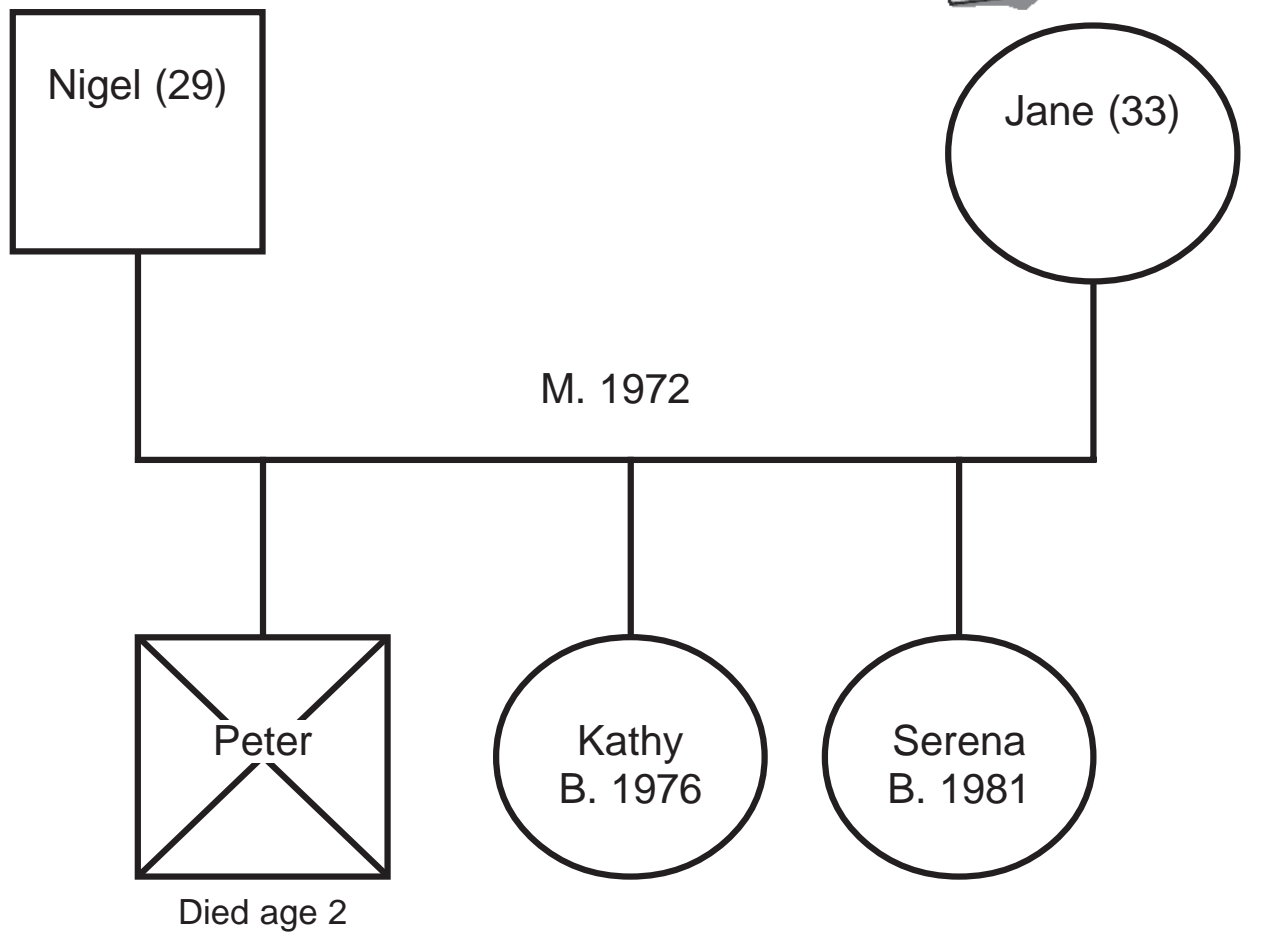

It is necessary to place the family structure within its dominant context; that is the prominent function or story of the family. If the family's dominant context is education, as in the case of the Ford family, a 
symbol would be placed inside the genograph representing education. The dominant context tells us that the family functions within an educational context, and their story is based on educational grounds. The following symbol illustrates the Ford family's dominant context:

\section{Education}

When we look at each individual within the family structure, each member also forms part of the family's social context. Each member's individual context will differ from the next. Nigel Ford is used as an example, portrayed in Figure 3 of such a genograph.

Figure 3. A visual representation of the dominant stories involved in Nigel Ford's life

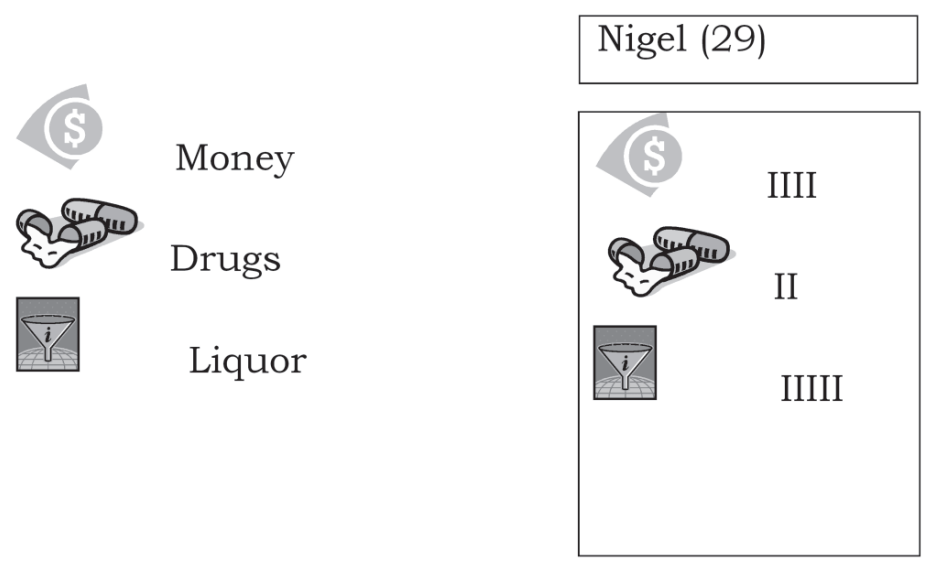

(The other members of the Ford family and their stories can be constructed in the same manner.)

Previously discussed in this article is the fact that symbols become part of our everyday action and interaction with others. Symbols prove that we are part of a social context. Various symbols can be used, and the counsellor and client can creatively develop their own set of symbols to suit the counselling session with regard to their dominant and alternative stories. The symbols chosen should represent the client's reality of their dominant stories and the counsellor should respect that. It is also important that the counsellor respect and accept symbols, chosen by family members, that represent alternative stories. Other family members may not accept these alternative stories or their social context and could lead to conflict and rejection in a family. The counsellor should also try to grasp the full meaning of the symbols 
and use it as the client perceives it. The following are examples of symbols that can be used:

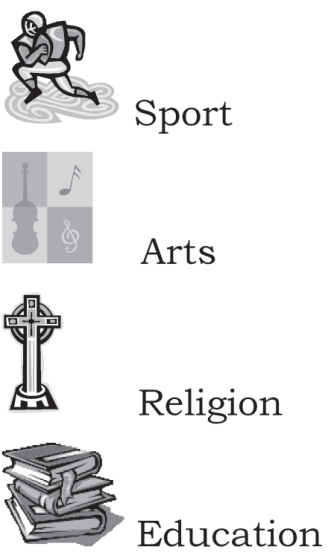

\section{Conclusion}

As with any counselling action that is effective, the handling of the genograph, within the dynamics of a family counselling or training group, presuppose a nuanced appreciation of the points where the persons and group in question are fragile. This also emphasizes the genograph's use in intercultural counselling. The genogram and genograph provide the counsellor with sufficient information about the family structure and its social contexts. It is therefore necessary that they discuss the client as a social being as well as the client's social reality. The information obtained from this can provide the counsellor with the client's personal narrative or story. It provides the counsellor and the family with symbolic representations of their individual sense of meaning and experience living their family stories. It becomes the catalyst for discussion about difference and understanding of diverse experience in the family. Both the genogram and genograph focuses on the counselling process on collaborative, agreed upon outcomes to enhance the co-construction. This will rewrite the negative dominant stories and create new positive dominant stories that will develop a life of its own and establish preferred family outcomes. The client's family context and individual stories can thus be discussed under the visual representation of the genograph.

\section{Bibliography}

ANDERSON, T. 1992. Reflections on reflecting with families. (In McNamee, S \& Gergen, K.J. eds. Therapy as social construction. London: SAGE Publications.) 
Van Niekerk, Van Niekerk, Mushonga and Dogger

ANDERSON, H. \& GOOLISHIAN, H.A. 1988. Human systems as linguistic systems: preliminary and evolving ideas about the implications for clinical theory. Family Process, 27(4):371-393.

ANDERSON, H. \& GOOLISHIAN, H.A. 1992. The client is the expert: a not knowing approach to therapy. (In McNamee, S. \& Gergen, K.J. eds. Therapy as social construction. London: SAGE Publications.)

ATWOOD, J.D. 1997. Social construction theory and therapy. (In Atwood, J.D. ed. Challenging family therapy situations: perspectives in social construction. New York: Springer .)

ATWOOD, J.D. \& SEIFER, M. 1997. Extramarital affairs and constructed meanings: a social constructionist therapeutic approach. The American Journal of Family Therapy, 25(1):55-75.

BACKUS, W. 1996. The Healing power of a Christian mind: how biblical truth can keep you healthy. Minneapolis: Bethany House.

BATESON, G. 1997. Mind and nature. New York: Dutton.

BECVAR, D.S \& BECVAR, R.J. 1996. Family therapy: A systematic integration. Boston: Allyn and Bacon.

BOHAN, J.S. 1990. Social constructionism and contextual history: an expanding approach to the history of psychology. Teaching of Psychology, 17(2):82-89.

BRUFFEE, K.A. 1986. Social construction, language, and the authority of knowledge: a bibliographical essay. College English, 48:773790.

BURGER, W.D. 2004. Fiksie en identiteitskonstruksie: 'n beskouing van selfnarratiewe. Johannesburg: Rand Afrikaanse University. (Unpublished MA. Dissertation.)

CARTER, E.A \& McGOLDRICK, M. 1980. The changing family life cycle: A framework for family therapy. New York: Gardner.

(—_.) 1989. The changing family life cycle: A framework for family therapy. Boston: Allyn \& Bacon.

CONNELL, R. 1987. Gender and power. Cambridge: Polity.

COOLEY, C.H. 1902. Human nature and the social order. New York: Scribner.

CORTAZZI, M. 1994. Narrative analysis in language teaching. Cambridge: Cambridge University Press.

CROSSLEY, M.L. 2000. Introducing narrative psychology: self, trauma and the construction of meaning. Buckingham: Open University Press. 
FERRANTE, F. 1998. Sociology: A global perspective. New York: Wadsworth.

FREEDMAN, J. \& COMBS, G. 1996. Narrative therapy: the social construction of preferred realities. New York: W.W. Norton \& Company.

GERGEN, K.J. 1999. An invitation to social construction. London: SAGE.

GERGEN, K.J. \& GERGEN, M.M. 1984. The social construction of narrative accounts. (In Gergen, K.J. \& Gergen, M.M. eds. Historical social psychology. Hillsdale: Lawrence Erlbaum.)

(—.) 1991. Toward reflexive methodologies. (In Steier, F. ed. Research and reflexivity. London: Sage)

HARE-MUSTIN, R.T. \& MARECEK, J. 1988. The meaning of difference: gender theory post-modernism and psychology. American Psychologist, 43:455-464.

HERMANS, H.J.M. 1999. Dialogical thinking and self-innovation. Culture and Psychology, 5(1):67-87.

HOFFMAN, L. 1992 A reflexive stance for family therapy. (In McNamee, S \& Gergen, K.J. eds. Therapy as social construction. London: SAGE.)

JORDAAN, W \& JORDAAN, J. 1998. People in context. Johannesburg: Heinemann.

KLUCKHOLM, C. 1985. Mirror for man: The relationship of anthropology to modern life. Tucson: University of Arizona Press.

KOTZE, E. \& KOTZE, D.J. 1997. Social construction as a post-modern discourse: an epistemology for conversational therapeutic practice. Acta Theologica, 1:27-50.

LAUNER, J. 1996. You're the doctor, doctor! Is social constructionism a helpful stance in the general practice consultations? Journal of Family Therapy, 18(3):255-267.

MAIR, M. 1988. Psychology as Storytelling. International Journal of Personal Construct Psychology, 1:125-138.

MEAD, G.H. 1934. Mind, self and society. Chicago: University of Chicago Press.

MOORE, T \& CARLING, C. 1988. The limitations of language. London: Macmillan.

RICHARDS, P.S. \& BERGIN, A.E. 1999. A spiritual strategy for counseling and psychotherapy. Washington: American psychological Association. 
Van Niekerk, Van Niekerk, Mushonga and Dogger

THOMAS, W.I \& THOMAS, D.S. 1928. The child in America. New York: Knopf.

WALLACE, R.C \& WALLACE, W.D. 1989. Sociology. London: Allyn and Bacon.

WEINGARTEN, K. 1991. The discourses of intimacy: Adding a social constructionist and feminist view. Family Process, 30:285-305.

WHITE, M. \& EPSTON, D. 1990. Narrative means to therapeutic ends. New York: Norton.

WULFF, D.M. 1997. Psychology of religion: classic and contemporary. New York: John Wiley \& Sons. 